\title{
Floral Morphology and Development in Georgia Plume, Elliottia racemosa (Ericaceae), a Rare Coastal Plain Endemic
}

\author{
Carrie A. Radcliffe, James M. Affolter, and Hazel Y. Wetzstein ${ }^{1}$ \\ Department of Horticulture, 1111 Miller Plant Science Building, The University of Georgia, Athens, \\ GA 30602-7273
}

\begin{abstract}
ADDitional INDEX wORDs. floral development, pollen viability, protandry, secondary pollen presentation, stigmatic receptivity, stigmatic exudate, viscin

Abstract. Georgia plume (Elliottia racemosa) is a threatened woody plant endemic to the Coastal Plain region of Georgia in the southeastern United States. Seed set is low in most populations, and sexual recruitment has not been observed in recent times. The objective of this study was to describe the floral biology of georgia plume. which is fundamental information needed to develop an understanding of the causes for lack of sexual reproduction in natural populations. Floral development was characterized and morphological characteristics at key developmental stages ranging from small, unopened buds to open flowers with receptive stigmas were examined using light and scanning electron microscopy. Flowering is protandrous, and anthers dehisce releasing pollen within closed buds before stigmas are receptive. Pollen tetrads, aggregated by viscin strands, are presented on unreceptive stigmas when petals reflex. Receptive stigmas developed a raised and lobed central region with a clefted opening leading to a stylar canal containing exudate produced in secretory regions. Receptivity of the non-papillate stigma is indicated by the formation of an exudate droplet, which is formed within 1 day after flower opening. Pollen viability was low to moderate; tetrad germination ranged from $20 \%$ to $40 \%$ using in vitro germination assays indicating poor pollen quality and may contribute to lack of seed development in some populations. No developmental abnormalities in stigmas or styles were observed indicating other factors are responsible for lack of sexual recruitment in the wild.
\end{abstract}

Elliottia racemosa, commonly known as georgia plume, is a threatened, woody plant that occurs only in the Coastal Plain region of Georgia in the southeastern United States. It was first discovered by the explorer William Bartram in 1773, documented by botanist Stephen Elliott in 1807, and so rare that the species was thought to be extinct until its rediscovery in 1901 . Georgia plume is a striking deciduous tree reaching heights of $9 \mathrm{~m}$ and can have a single or multitrunked form. Plume-like racemes of attractive, white flowers appear in early summer above lustrous, green foliage. Despite all of its positive horticultural attributes, georgia plume has a limited range not only in the wild, but also in cultivation. It is difficult to propagate and characteristically exhibits extremely rare fruit production, scarcity of ripe seed, and difficulty with transplanting (Del Tredici, 1987).

Georgia plume grows on sand ridges, dry oak ridges, evergreen hammocks, and sandstone outcrops (Patrick et al., 1995). The apparently wide variety of habitats, but limited number of locations in which georgia plume occurs, has made it difficult to draw any definitive conclusions as to causes for rarity of the species. Georgia plume is reported to be found in less than three dozen populations (Chafin, 2007). However, our recent work conducting population surveys to develop a Global Positioning System/Geographic Information System-based conservation management tool for georgia plume indicates that many recorded populations no longer exist with human activity

Received for publication 2 July 2010. Accepted for publication 20 Aug. 2010. We thank Ron Determann and the Atlanta Botanical Garden for the use of Elliottia plants in their collection and Martha Joiner for her invaluable assistance in the field.

${ }^{1}$ Corresponding author. E-mail: hywetz@uga.edu. being a major cause (Porter, 2010). The distribution of georgia plume has been fragmented by land development and habitat decline.

Nonetheless, reproductive problems associated with this species appear to contribute to the rarity of this plant. Plants are observed to flower freely in the wild; however, fruit capsules are few and often contain inviable seed (H.Y. Wetzstein, unpublished data). No or limited seed production has been noted by several authors (Del Tredici, 1987; Faircloth, 1970; Fordham, 1991). In recent times no seedlings have been documented in the wild, indicating an absence of sexual recruitment. Some limited studies using artificial hand pollinations with self- and cross-pollen have been largely unsuccessful (reviewed by Santamour, 1967). The main mode of reproduction for georgia plume is thought to be vegetative through root suckers, but plant regeneration is extremely limited. Low population numbers and a lack of sexual reproduction may lead to the demise of this plant, which has low genetic diversity at both the population and species level (Godt and Hamrick, 1999). It is listed as threatened in the state of Georgia but has no U.S. Federal listing.

There is a lack of scientific knowledge about this species in general, and little is known about the reproductive biology of georgia plume and the underlying causes for lack of sexual reproduction. As part of an overall effort in the conservation of georgia plume, our current work has focused on surveys of existing populations, propagation, and safeguarding. Georgia plume cannot be effectively propagated using conventional methods. Using cuttings is not successful, and limited seed availability is problematic. We have developed a tissue culture protocol that is effective with mature field-collected material (Woo and Wetzstein, 2008a, 2008b), and genotypes from a 
number of populations are being maintained in vitro. Field testing of tissue culture regenerated plants is underway in native habitats (Wetzstein and Yi, 2010). However, the long-term viability of this species is dependent on successful reproduction occurring in the wild. Critical information on fundamental aspects of floral development are needed to develop an understanding of what factors are causing lack of sexual reproduction in native habitats. Causes of unfruitfulness in plants can be multifold and may include abnormal flower development, inviability of pollen, self-incompatibility, lack of genetic diversity, and pollinator limitation (Franklin-Tong, 2002, Takayama and Isogai, 2005; Wilcock and Neiland, 2002). We have been conducting studies in an effort to develop a better understanding of the reproductive biology of georgia plume, including flower development, controlled pollination, and phenology studies. The objectives of the work described in this current study are to define and characterize the floral developmental stages in georgia plume, investigate stigma receptivity and anther development, and assess pollen viability. Such information may be used to identify underlying factors responsible for the lack of sexual reproduction in natural populations.

\section{Materials and Methods}

Plant material. The flowers used in this study were from nursery-grown plants in the Atlanta Botanical Garden's conservation collection. Plants were $\approx 90$ to $120 \mathrm{~cm}$ tall and potted in 11-L pots. Plants represented genotypes from a population in the Big Hammock Natural Area in Tattnall County, GA. Flowers were open-pollinated in the nursery. Distinct stages of floral development were defined initially based on macroscopic differences, including bud size and color (Fig. 1). At least 10 flowers were collected and fixed for each stage. Light microcopy sections were made with six flowers; additional flowers were prepared for scanning electron microscopy (SEM). The classification and staging of flowers were based on very specific macroscopic flower characteristics. Thus, within a stage, histological development was found to be very consistent among flower samples. Pollen used in germination assays was from inflorescences collected in the field from the Big Hammock Natural Area in Tattnal County, GA; Charles Harrold Nature Preserve in Candler County, GA; Manassas Bog in Tattnal County, GA; and a population in Turner County, GA.

Microscopy Methods. Flowers representing each stage were dissected and prepared using methods described by Woo and Wetzstein (2008a) for SEM. Flowers were fixed in $2 \%$ glutaraldehyde in $0.1 \mathrm{M}$ cacodylate buffer, washed in the same buffer, serially dehydrated using ethanol, and critical point dried with carbon dioxide using a critical point drier (Samdri-790; Tousimis Research, Rockville, MD). Dried samples were mounted on aluminum stubs using carbon conductive tabs and sputter-coated (SPI-Module; SPI Supplies, West Chester, PA) with $60 \mathrm{~nm}$ gold. Samples were observed at 15 kV using a SEM (JSM 5800; JEOL, Tokyo, Japan). To better assess the development of stigmatic exudate, some fresh tissue samples were observed. Pistils were dissected; stigmas and styles were mounted on stubs using conductive tabs and immediately viewed using the SEM.

For light microscopy, flowers at each stage were dissected, fixed using tissue fixative (Histochoice; Amresco, Solon, $\mathrm{OH}$ ), and dehydrated through a graded ethanol series. Samples were then infiltrated and embedded in glycol methacrylate (JB-4 embedding kit; Polysciences, Warrington, PA). Serial sections were made of six flowers per stage cut into 5 - $\mu \mathrm{m}$ sections using a rotary microtome (Microm, Heidelberg, Germany). Sections were mounted, stained, and examined using a light microscope (BX51; Olympus America, Center Valley, PA). For general histological observations, sections were stained with $1 \%$ acid fuchsin (w/v) and $0.05 \%$ toluidine blue $\mathrm{O}(\mathrm{w} / \mathrm{v})$. Periodic acidSchiff was used to localize polysaccharides using a saturated solution of dimedone as an aldehyde blocking reagent. Proteins were localized with $0.1 \%$ Coomassie Blue in water:methanol: acetic acid (87:10:1, v/v). Cuticles were visualized using 0.01\% Auramine $\mathrm{O}(\mathrm{w} / \mathrm{v})$ in Tris- $\mathrm{HCl}$ buffer $(\mathrm{pH}$ 7.2) under fluorescent light.

Pollen tube growth ANd viability. Pollen tube germination and growth within the styles were assessed using aniline blue and fluorescence microscopy as described by $\mathrm{Yi}$ et al. (2006). Stigmas and styles were dissected and fixed in ethanol: acetic acid $3: 1(\mathrm{v} / \mathrm{v})$. Tissues were softened by autoclaving at $120{ }^{\circ} \mathrm{C}$ for $10 \mathrm{~min}$ in $1 \%$ sodium sulfite solution $(\mathrm{w} / \mathrm{v})$, stained with aniline blue $\left(0.01 \%\right.$ aniline blue in $\left.0.1 \mathrm{M} \mathrm{K}_{3} \mathrm{PO}_{4}\right)$, then examined under transmitted and ultraviolet light using a light microscope (BX51).

In vitro germination assays were conducted according to $\mathrm{Yi}$ et al. (2003). Pollen was inoculated in microwell plates using a standard germination medium $\left(0.062 \% \mathrm{CaNO}_{3}\right.$ and $0.024 \%$ boric acid) containing 15\% sucrose. Germinating pollen was viewed and counted using an inverted microscope (DIAPHOT; Nikon, Garden City, NY). Tetrads were considered germinated if one or more tubes extended a length greater than the diameter of a pollen grain.

\section{Results}

Inflorescences of georgia plume are 7.5 to $30 \mathrm{~cm}$ long and borne terminally. There are 25 to 60 flowers per inflorescence, which open acropetally from the base to the tip of an inflorescence. Flowers have four or five free petals, 12 to $16 \mathrm{~mm}$ long, which are strongly reflexed when flowers are open. Nectaries are inside flowers and concealed by the petals and are reported to contribute to the faint scent of the flowers (Bohm et al., 1978). There are eight to 10 stamens per flower. The ovary is superior with four to five locules, each with five to eight ovules. Fruit are capsules roughly $1 \mathrm{~cm}$ in diameter, which dehisce septicidally and contain winged seed.

Distinct stages of floral development were initially defined according to bud size and petal parameters (Fig. 1) ranging from immature, closed buds to receptive flowers with reflexed petals. Macroscopic characteristics of flower stages were as follows and shown in Figure 1: Stage A buds were 4 to $6 \mathrm{~mm}$ long, green or greenish white in color, and held upright on pedicles; Stage B buds were greater than 6 to $9 \mathrm{~mm}$ long, white, and nodding; Stage $\mathrm{C}$ buds were greater than 9 to $14 \mathrm{~mm}$ long, pendulous, and with petals distally attached but separated in the median regions; Stage D flowers were open with petals reflexed. Individual flowers progressed from Stage A through Stage $D$ in $\approx 9 \mathrm{~d}$. Each stage was analyzed microscopically in greater detail.

Although Stage A buds (Fig. 2A) were immature and small (4 to $6 \mathrm{~mm}$ long), the stigma and anthers were well differentiated (Fig. 2B). Stamens extended to approximately half the 


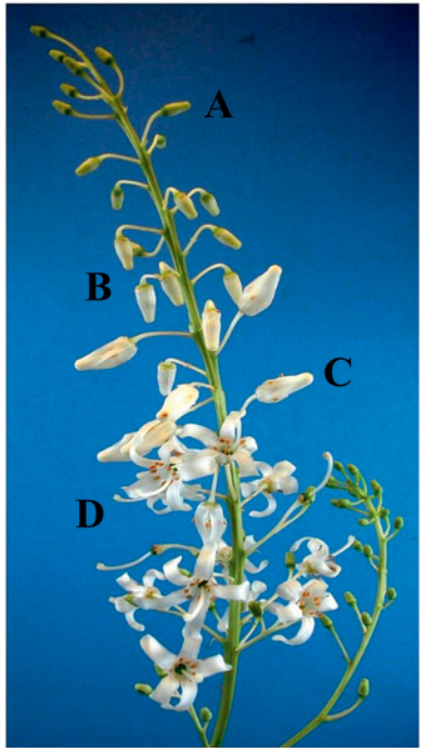

Fig. 1. Inflorescence of georgia plume showing acropetal opening of flowers. Different developmental stages (A-D) are labeled and described in subsequent figures.

length of the buds, and anthers already were partially to fully dehisced. Anther dehiscence originated at circular, pore-like regions at the tips of anthers (Fig. 2B) and continued longitudinally along the length of the anther walls. Light micrographs of anthers in crosssection show pollen, in tetrads of four fused pollen grains, still enclosed within partially dehisced anther sacs inside immature buds (Fig. $2 \mathrm{C}$ ). Tetrads measured $\approx 50 \mu \mathrm{m}$ in diameter and were associated with filamentous strands that kept the tetrads aggregated in large clumps (Fig. 2D). Particulate material was seen on stigmas and was most likely remnants of tapetal material released from anthers (Fig. 2E-F). The disk-shaped stigmatic surfaces appeared smooth and non-papillate with clefted openings visible in the center (Fig. 2E). There was no evidence of exudate. Cross-sections of epidermal cells lining the stigmatic opening stained darkly and were well differentiated (Fig. 2G). Cells adjacent to clefted region stained lightly, were undifferentiated, and undergoing cell division.

In Stage B (Fig. 3A), buds were larger (greater than 6 to $9 \mathrm{~mm}$ long) and pendulous. Dehisced anthers were completely empty (Fig. 3B), and pollen clumps aggregated within
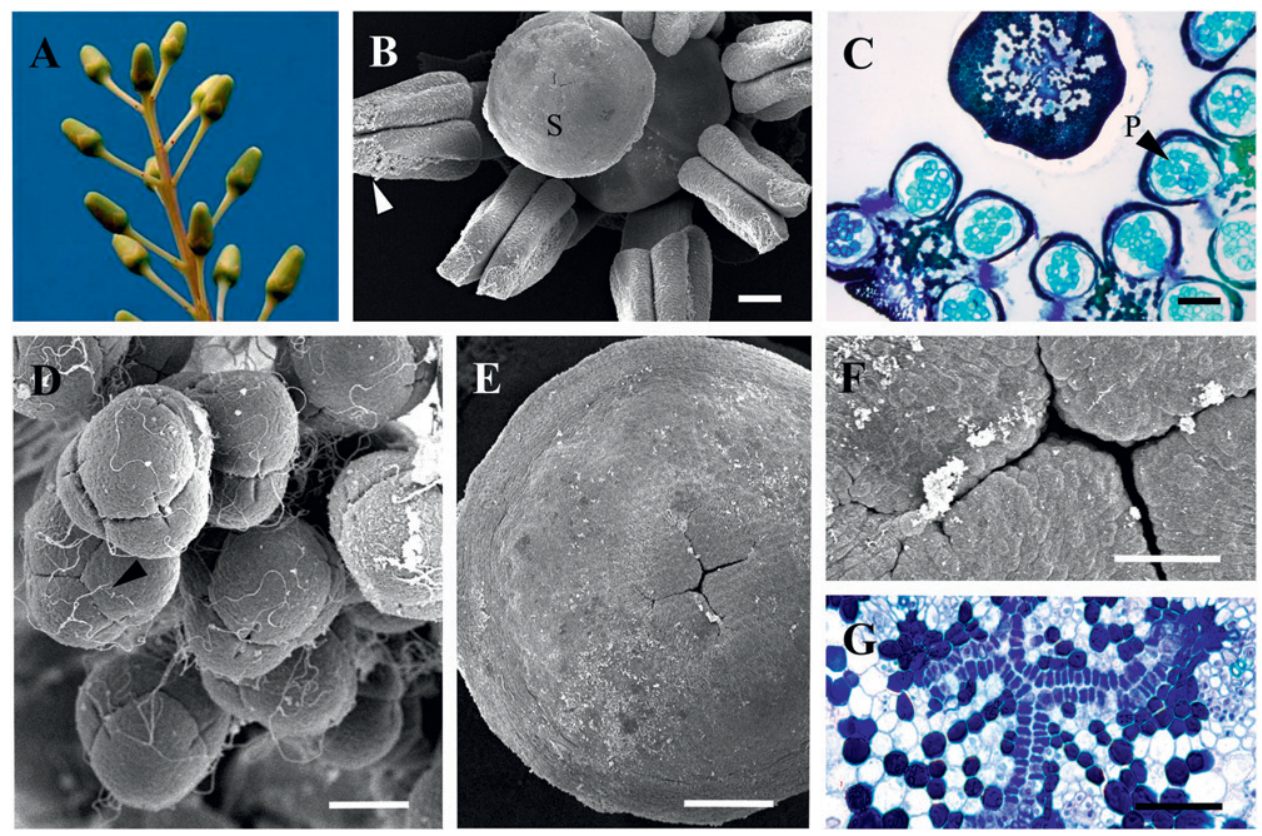

Fig. 2. Micrographs of georgia plume flowers at Stage A when flowers are closed buds, 4 to $6 \mathrm{~mm}$ long, and upright on pedicles. (A) Stage A flower buds. (B) Scanning electron microscopy of immature bud with petals removed, showing stigma (S) with shortened pistil surrounded by anthers exhibiting dehiscence at tips (point). (C) Crosssection of flower showing pollen within anther sacs (point) that surround the stigma. (D) Pollen tetrads aggregated in clumps with viscin threads (point). (E) Disc-shaped stigmatic surface with a narrow central cleft. (F) Powdery tapetal material on the smooth stigmatic surface. (G) Cross-section of stigmatic surface, similar to area shown in $\mathbf{F}$, showing epidermal cells lining the stigmatic cleft. Scale bars: $\mathbf{B}, \mathbf{C}, \mathbf{E}=200 \mu \mathrm{m} ; \mathbf{D}=20 \mu \mathrm{m}$; $\mathbf{F}, \mathbf{G}=50 \mu \mathrm{m}$
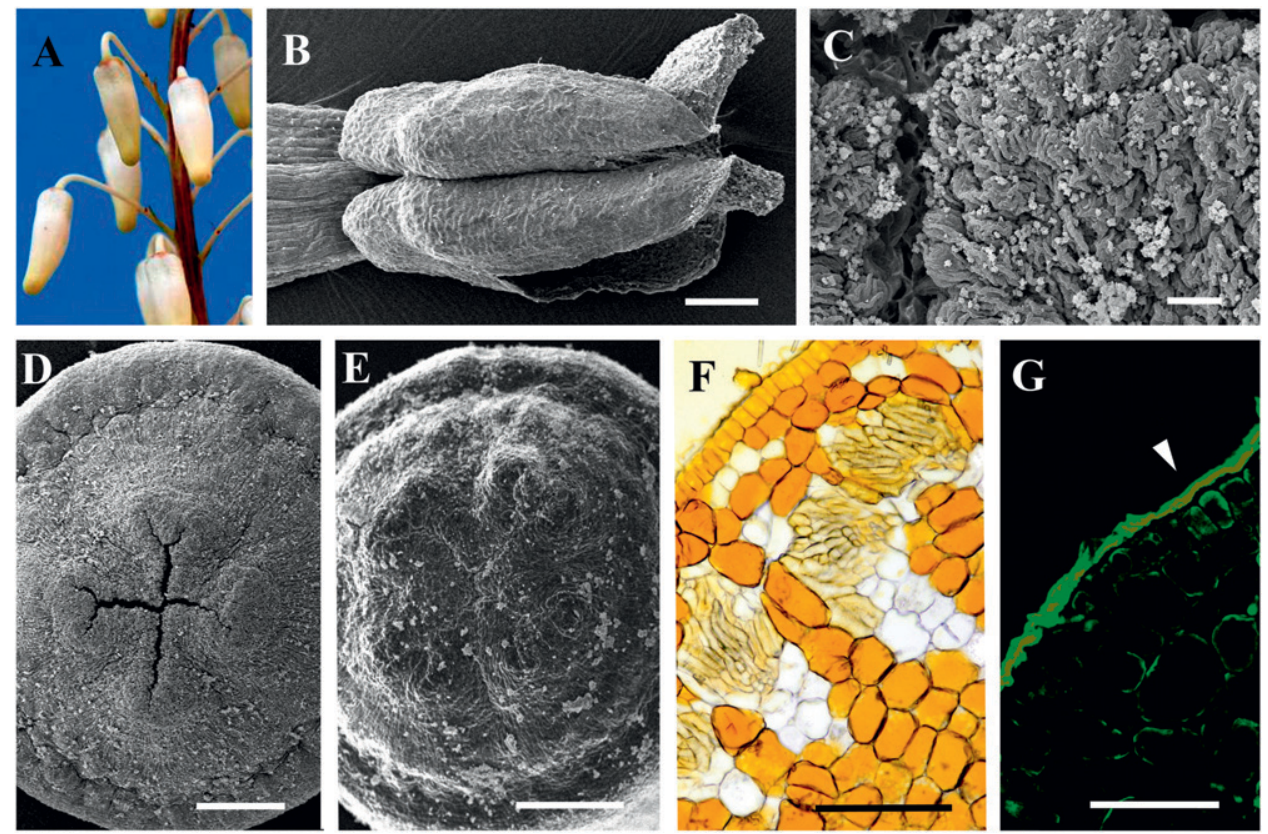

Fig. 3. Micrographs of georgia plume flowers at Stage B when flowers are closed buds, greater than 6 to $9 \mathrm{~mm}$ long, and pendulous. (A) Stage B flower buds. (B) Scanning electron microscopy of anthers removed from within a closed bud that have dehisced and released pollen. (C) Higher magnification of stigmatic surface showing tapetal residues. (D) Conventionally fixed and critical point dried stigma showing stigmatic cleft. (E) Fresh, unfixed stigma with stigma secretions preserved. (F) Longitudinal section of stigma revealing glandular regions containing secretory cells. (G) Light micrograph of stigmatic surface stained with auramine O and viewed with ultraviolet light showing fluorescence of an intact cuticle that covers the stigma at this stage. Scale bars: $\mathbf{B}, \mathbf{D}, \mathbf{E}$, $\mathbf{F}=200 \mu \mathrm{m} ; \mathbf{C}=10 \mu \mathrm{m} ; \mathbf{G}=50 \mu \mathrm{m}$ 
the tips of the flower buds where petals were distally attached. Bud enlargement was the result of petal elongation; stamens were approximately one-third of the total bud length. As buds elongated, pistils likewise increased in length so that stigmas were appressed to the distal portion where petals were fused at the apex. By this stage, stigmas had developed a mounded appearance. Under higher magnifications, the stigmatic surfaces appeared textured and had tapetal and other particulate materials on the surface (Fig. 3C). The clefted opening in the center of the stigma became more prominent as four surrounding lobes began to develop evident in fixed (Fig. 3D) and fresh (Fig. 3E) samples. Some pollen tetrads were observed on the stigmatic surface of fresh, unfixed tissues (Fig. 3E). Conventional fixation and dehydration removed surface residues and all pollen grains, indicating that stigmas at this stage failed to capture and adhere pollen (Fig. 3D). Secretory glands were differentiated in the subsurface layers of the stigma. Each glandular region consisted of loosely arranged cells and was located between the clefts of the stigmatic opening (Fig. 3F). Stigmas remained relatively free of surface secretions at this stage and had an intact cuticle covering the stigma shown with auramine $\mathrm{O}$ staining (Fig. 3G).

Stage C buds (Fig. 4A) were greater than 9 to $14 \mathrm{~mm}$ long, pendulous, and with petals distally attached but showing separation in the median regions. Pistils extended the full length of buds and developed a curved configuration near the stigma-style interface. Stigmas were more mounded than the previous stage (Fig. 4B versus Fig. 3D) and had more prominent clefted openings (Fig. 4D). Stigmatic lobes were surrounded by a circular outer rim that defined the stigmatic region (Fig. 4B). Cross-sections showed that styles were solid and lacked a central canal at this time (Fig. 4C). Under higher magnifications, stigmas were more noticeably textured (Fig. 4E). Stigmas were appressed into cup-shaped regions formed where petals coalesced distally, and when flowers were dissected to open petals, some pollen remained on the
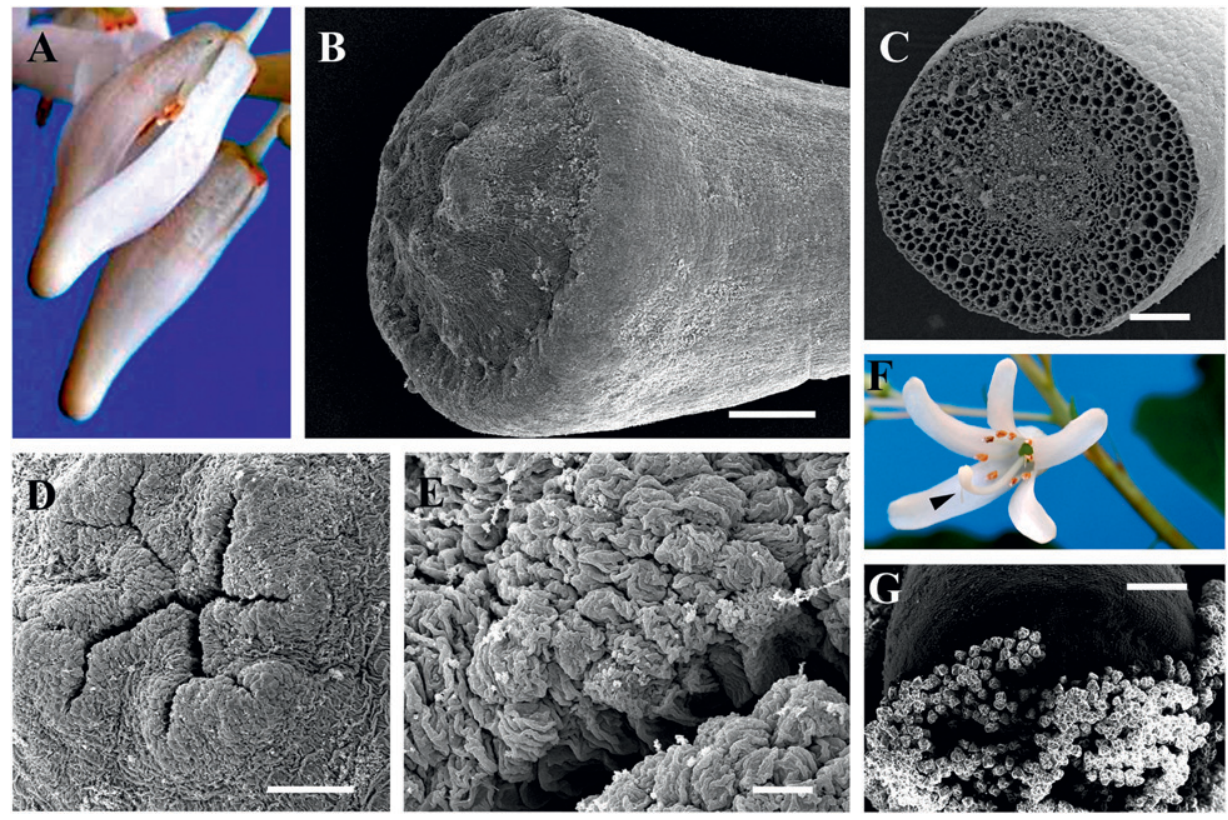

Fig. 4. Micrographs of georgia plume flowers at Stage C with petals separating (A-E) and Stage D when flowers are open with reflexed petals $(\mathbf{F}-\mathbf{G})$. (A) Stage $C$ flowers are greater than $9 \mathrm{~mm}$ long with petals separating in the median region. (B) Scanning electron micrograph (SEM) of Stage C stigmatic surface showing mounded central region surrounded by circular ridge. (C) SEM cross-section of Stage C flower showing solid style. (D) Mounded stigmatic surface of Stage C flower with prominent cleft. (E) Textured stigmatic surface cells on Stage C flower. (F) Stage D flower showing pollen presentation on an unreceptive stigma (point) with reflexed petals. (G) SEM of Stage D flower showing clumps of pollen presented on a fresh, unfixed stigma. Scale bars: $\mathbf{B}, \mathbf{G}=200 \mu \mathrm{m}$; $\mathbf{C}, \mathbf{D}=100 \mu \mathrm{m} ; \mathbf{E}=10 \mu \mathrm{m}$.
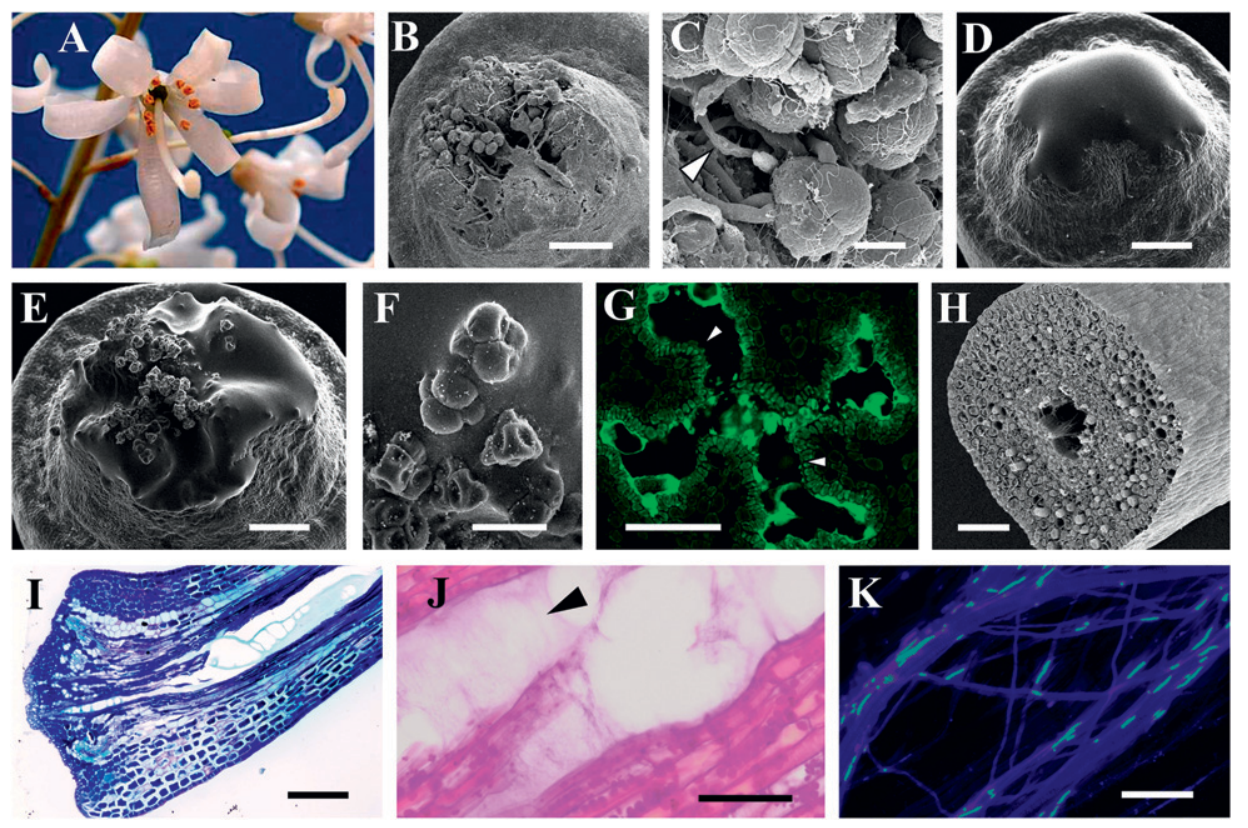

Fig. 5. Micrographs of georgia plume flowers at Stage D with reflexed petals. (A) Stage D flowers with petals reflexed. (B) Scanning electron micrograph (SEM) of conventionally fixed stigma; most of the exudate has washed away, exposing pollen tetrads and pollen tubes in the clefted region. (C) Higher magnification showing germinated pollen and tubes (point). (D) Fresh, unfixed SEM sample with copious exudate obscuring the clefted region of the stigma. (E) Fresh, unfixed SEM of stigma with pollen captured in exudate. (F) Higher magnification of $\mathbf{E}$ showing both hydrated and non-hydrated pollen tetrads. (G) Light micrograph of stigmatic cleft cross-section stained with auramine O showing discontinuous cuticle (point) after exudate secretion. (H) SEM cross-section of style revealing a central canal. (I) Longitudinal section of stigma and portion of style revealing a lysigenous stylar canal converging with the stigmatic cleft. (J) Longitudinal section of stylar canal region showing Periodic acid-Schiff-positive staining exudate within the canal (point). (K) Pollen tubes growing within the stylar canal stained with aniline blue and viewed under ultraviolet irradiation. Scale bars: B, D, $\mathrm{E}=200 \mu \mathrm{m} ; \mathbf{C}=20 \mu \mathrm{m} ; \mathbf{F}, \mathbf{K}=50 \mu \mathrm{m} ; \mathbf{G}, \mathbf{H}, \mathbf{J}=100 \mu \mathrm{m} ; \mathbf{I}=250 \mu \mathrm{m}$. 
stigmatic surfaces. However, exudate was lacking, pollen did not adhere, and no pollen germination was observed at this stage.

Stage D (Fig. 4F) flowers were open with petals reflexed and styles curved. Pollen was frequently presented on the unreceptive stigmas of flowers that had just opened (Fig. 4F-G). Stigmas lacked surface exudate when petals first reflexed; exudate was not secreted until 6 to $24 \mathrm{~h}$ after flower opening (Fig. 5A). Pollen capture and germination followed exudate secretion and was restricted to the central cleft where exudate accumulated as shown in conventionally fixed and critical point dried samples (Fig. 5B-C). A widened stigmatic opening is evident in Figure 5B where exudate was partially removed during the fixation process. Observations of fresh, unfixed samples (Fig. 5D-F) showed the copious amounts of exudate accumulated in the stigmatic cleft. Stigmas did not develop papillae. Pollen tetrads adhered to the stigma (Fig. 5E) and became hydrated when immersed in exudate (Fig. 5F). Pollen tubes of the germinated tetrads penetrated the clefted opening (Fig. 5B). The clefted openings were well defined by an epidermal layer and cuticle. The cuticular layer lining the stigmatic opening became discontinuous after exudate secretion (Fig. 5G). A stylar canal (Fig. 5H) was not observed until flowers reached this stage and converged with the stigmatic opening (Fig. 5I). Canals were hollow, lysigenous, and lacked epidermal cells. Exudate stained positively for polysaccharides (Fig. 5J) but negatively for proteins.

Pistils stained with aniline blue showed that numerous pollen tubes could grow within the central canal (Fig. 5K). Pollen tube growth was not observed in pistils until after exudate secretion occurred on open flowers (Fig. 5K). In vitro pollen germination assays revealed that viability of the tetrads was low. Germination of pollen tetrads collected from four populations in the wild ranged from $25 \%$ to $42 \%$. The average number of pollen tubes per tetrad ranged from 1.1 to 1.6.

\section{Discussion}

Georgia plume displays many floral traits similar to other members of the Ericaceae (Hermann and Palser, 2000; Hesse, 1983; Lu et al., 2009; Palser et al., 1992; Williams and Rouse, 1990; Zomlefer, 1994); anthers dehisce longitudinally, and binucleate pollen is borne in tetrads of four fused pollen grains connected by viscin strands. Several studies have commented on the effect of viscin on pollen dispersal. Viscin threads function to hold pollen together in clumps and enhance pollen transfer efficiency (Cruden and Jensen, 1979; Smithhuerta, 1991). Fossilized flowers belonging to Ericales with viscin strands suggest that specific pollinator-plant relationships existed as early as the mid-Cretaceous period (Nixon and Crepet, 1993). Pollination by bumble bees is facilitated by low-frequency vibration of anthers and viscin threads in Rhododendron spp. (King and Buchmann, 1995). In Berberis thunbergii, pollen clumps held together by viscin were removed partially by a number of floral visitors (Lebuhn and Anderson, 1994). Such a pattern should prevent pollen from being disseminated completely to one floral visitor and promote more effective gene dispersal (Erbar and Leins, 1995). The aggregation of pollen in clumps by viscin is thought to prevent wind dispersal (Kevan et al., 1991).

E. racemosa can be considered protandrous, because pollen is available for outcrossing when flowers first open, before exudate production and the onset of stigma receptivity, which occurs 6 to $24 \mathrm{~h}$ after petal opening. Plants that exhibit pollen presentation by secondary means are almost always protandrous (Howell et al., 1993). Secondary pollen presentation exists when pollen undergoes an intermediate transfer from anthers to a presenting structure, making it available for transfer by biotic or abiotic means (Ladd, 1994). Although there is no structure adapted solely to this function in georgia plume, the unreceptive stigmas can bear pollen in large clumps held together by viscin. In the absence of stigmatic exudate, pollen does not germinate and is easily removed by floral visitors. However, if autogamous pollen is still present when stigmas become receptive, lack of available space may prevent outcross pollen from landing and germinating on the stigmatic surface. This is very similar to Cephalanthus occidentalis, which likewise presents its pollen on unreceptive stigmas (Imbert and Richards, 1993). In C. occidentalis, pollen is shed onto stigmas within closed buds and removed by pollinators after flowers open. Increased risks of self-pollination can be offset or even overcome by selfincompatibility. C. occidentalis exhibits gametophytic selfincompatibility, which allows pollen tubes to penetrate stigmas but prevents self-fertilization by inhibiting growth of tubes within the style. The amount of selfing versus outcrossing depends on the timing and degree of self-pollen removal and also the precise timing of stigmatic receptivity. Even when an incompatibility system is operative, the presence of large loads of self-pollen can "clog" stigmas and exclude compatible pollen (Howell et al., 1993). Further work is needed to determine if self-incompatibility exists in E. racemosa.

The stigma of georgia plume is of the wet, non-papillate type. Stigmas of Rhododendron spp. are also characterized as such. In E. racemosa, receptivity is indicated by the formation of an exudate droplet that develops after petals reflex and flowers are open. Exudate formation is delayed until 6 to $24 \mathrm{~h}$ after buds open. Delayed stigmatic receptivity is seen in other species, including Collinsia heterophylla (Lankinen et al., 2007), Prunus dulcis (Yi et al., 2006), and Vaccinium ashei (Brevis et al., 2006). Stigmas of E. racemosa lack papillae and develop a raised and lobed central region with a clefted opening to the stylar canal where exudate is secreted. As described by Heslop-Harrison and Shivanna (1977), wet stigmas have noticeable, free-flowing secretions on the surface when receptive. Other Ericaceous genera with wet, non-papillate stigmas include Azalea, Gaultheria, Kalmia, and Rhododendron. Other plants in the wet non-papillate category commonly display protandry, as is seen in Liliaceae and Bromeliaceae, where flowers appear dry on opening followed by production of copious exudate between the stigmatic lobes (Heslop-Harrison and Shivanna, 1977).

A proteinaceous pellicle was not found in mature flowers of georgia plume but is normally only observed in dry stigma types. Ericaceous plants are known to have either smooth or papillate stigmas but are almost all wet (Heslop-Harrison, 1981). In E. racemosa, exudate is produced and secreted from the glandular region in the subsurface layers of the stigma. Secretory cells are arranged loosely, forming large intercellular spaces as the flowers mature. At the time of exudate secretion, the stigmatic cleft widens, epidermal cells lining the opening become separated, and the cuticular lining ruptures. This is similar to the structures and process present in Nicotiana sylvestris and N. tabacum, which have a subepidermal secretory zone in the stigma that converges into the transmitting tract 
of the style (Cresti et al., 1986; Kandasamy and Kristen, 1987). In many species with wet stigma types, exudate is secreted through exocytosis by the endoplasmic reticulum (Shivanna, 2003). Exocytotic secretion is associated with exudate release in other species that posses similarly organized glandular regions in their pistils (Cresti et al., 1986; Janson et al., 1994; Mackenzie et al., 1990).

The stigmatic opening in georgia plume converges with a hollow, lysigenous stylar canal that forms as the tubular core cells disintegrate during elongation of the style. Lysigenous canal development is also found in Colophospermum mopane, creating a continuum from stigma to ovary after the dissolution of core cells in the style (Jordaan et al., 2002). Hollow canals are able to accommodate growth of hundreds of pollen tubes (Schmidt-Adam and Murray, 2002). Exudates found within the hollow stylar canals of Rhododendron spp. also stain positively for polysaccharides (Palser et al., 1992). Exudates containing sugars are thought to serve as a carbon source for large numbers of growing pollen tubes (Schmidt-Adam and Murray, 2002; Slater and Calder, 1990).

Pollen viability for E. racemosa may be considered low on a per-pollen basis or moderate per tetrad and varied among the four populations observed. Tetrad germination ranged from $25 \%$ to $42 \%$. On average, less than two pollen grains per tetrad germinated. Results in this study were similar to low estimates of pollen tetrad viability $(20 \%)$ using aceto-carmine staining (Santamour, 1967). It was suggested that excessive inbreeding could have resulted in the accumulation and fixation of deleterious recessive genes, leading to low pollen viability. Population size and genotypic diversity vary among populations of $E$. racemosa, but genetic diversity within some populations was found to be low (Godt and Hamrick, 1999). Population surveys by Porter (2010) found that many of the active georgia plume populations are composed of few individuals with $75 \%$ of visited sites containing fewer than 50 individuals. Because populations are relatively small and isolated, inbreeding among closely related individuals is likely to occur even if this species is self-incompatible. We are conducting genetic studies to assess if the decline of this species may be related to its fragmented distribution and low-level diversity.

This study describes flower development and morphology for E. racemosa. Georgia plume is protandrous and exhibits secondary pollen presentation on unreceptive stigmas. Although anther dehiscence occurs early within flower buds, pollen capture is spatially and temporally limited to a central region of the stigma surrounding the opening to a lysigenous stylar canal where exudate is secreted at receptivity. E. racemosa has a wet non-papillate stigma type. The presence of exudate on the stigmatic surface is critical to pollen capture, hydration, and germination. Copious exudate rich in polysaccharides and a hollow stylar canal can support the growth of large numbers of pollen tubes. Pollen viability is low to moderate per tetrad and may contribute to lack of seed production in some populations. However, no abnormalities in stigma development or stylar anatomy were observed. In controlled cross-pollinations, we have examined flower preparations having large numbers of pollen tubes growing within stylar canals (data not given). Additional evaluations of ovule development as well as fertilization and embryogenesis are warranted. Reproductive failure can result from anomalous ovule development as shown in a study investigating the causes of low fruit set in 'Ziraat' sweet cherry (Prunis avium) (Mert and Soylu, 2007). Further- more, pollination failure can contribute to reproductive failure as a result of dispersal failure, pollinator limitation, inviability of pollen, insufficient pollen, and breeding systems. Georgia plume has protandrous presentation of pollen in clumps held together with viscin threads. Pollinator function is critical in such a system, particularly if this is associated with selfincompatibility. Further studies addressing these potential causes for unfruitfulness are warranted.

\section{Literature Cited}

Bohm, B.A., S.W. Brim, R.J. Hebda, and P.T. Stephens. 1978. Generic limits in the tribe Clodothamneae and its position in the Rhododendroideae. J. Arnold Arbor. 59:311-337.

Brevis, P.A., D.S. NeSmith, and H.Y. Wetzstein. 2006. Flower age affects fruit set and stigmatic receptivity in rabbiteye blueberry. HortScience 41:1537-1540.

Chafin, L.G. 2007. Field guide to the rare plants of Georgia. State Botanical Garden of Georgia, Athens, GA.

Cresti, M., C.J. Keijzer, A. Tiezzi, F. Ciampolini, and S. Focardi. 1986. Stigma of Nicotiana: Ultrastructural and biochemical studies. Amer. J. Bot. 73:1713-1722.

Cruden, R.W. and K.G. Jensen. 1979. Viscin threads, pollination efficiency and low pollen-ovule ratios. Amer. J. Bot. 66:875-879.

Del Tredici, P. 1987. Lost and found: Elliottia racemosa. Arnoldia 47: 3-8.

Erbar, C. and P. Leins. 1995. Portioned pollen release and the syndromes of secondary pollen presentation in the CampanulalesAsterales-complex. Flora 190:323-338.

Faircloth, W.R. 1970. An occurrence of Elliottia in central south Georgia. Castanea 35:58-61.

Fordham, A.J. 1991. Elliottia racemosa and its propagation. Arnoldia 51:59-62.

Franklin-Tong, V.E. 2002. The difficult question of sex: The mating game. Curr. Opin. Plant Biol. 5:14-18.

Godt, M.J.W. and J.L. Hamrick. 1999. Population genetic analysis of Elliottia racemosa (Ericaceae), a rare Georgia shrub. Mol. Ecol. 8: 75-82.

Hermann, P.M. and B.E. Palser. 2000. Stamen development in the Ericaceae. I. Anther wall, microsporogenesis, inversion, and appendages. Amer. J. Bot. 87:934-957.

Heslop-Harrison, Y. 1981. Stigma characteristics and angiosperm taxonomy. Nord. J. Bot. 1:401-420.

Heslop-Harrison, Y. and K.R. Shivanna. 1977. The receptive surface of the angiosperm stigma. Ann. Bot. (Lond.) 41:1233-1258.

Hesse, M. 1983. Dissimilar pollen tetrad development in Ericaceae and Onagraceae causes family-specific viscin thread configuration. Plant Syst. Evol. 143:163-165.

Howell, G.J., A.T. Slater, and R.B. Knox. 1993. Secondary pollen presentation in angiosperms and its biological significance. Aust. J. Bot. 41:417-438.

Imbert, F.M. and J.H. Richards. 1993. Protandry, incompatibility, and secondary pollen presentation in Cephalanthus occidentalis (Rubiaceae). Amer. J. Bot. 80:395-404.

Janson, J., M.C. Reinders, A.G.M. Valkering, J.M. Vantuyl, and C.J. Keijzer. 1994. Pistil exudate production and pollen tube growth in Lilium longiflorum Thunb. Ann. Bot. (Lond.) 73:437-446.

Jordaan, A., D.C.J. Wessels, and H. Kruger. 2002. Structure of the style and wet non-papillate stigma of Colophospermum mopane. Caesalpinioideae: Detarieae. Bot. J. Linnean Soc. 139:295-304.

Kandasamy, M.K. and U. Kristen. 1987. Developmental aspects of ultrastructure, histochemistry and receptivity of the stigma of Nicotiana sylvestris. Ann. Bot. (Lond.) 60:427-437.

Kevan, P.G., J.D. Ambrose, and J.R. Kemp. 1991. Pollination in an understory vine, Smilax rotundifolia, a threatened plant of the Carolinian forests in Canada. Can. J. Bot. 69:2555-2559.

King, M.J. and S.L. Buchmann. 1995. Bumble bee initiated vibration release mechanism of Rhododendron pollen. Amer. J. Bot. 82:1407-1411. 
Ladd, P.G. 1994. Pollen presenters in the flowering plants; form and function. Bot. J. Linn. Soc. 115:165-195.

Lankinen, A., W.S. Armbruster, and L. Antonsen. 2007. Delayed stigma receptivity in Collinsia heterophylla (Plantaginaceae): Genetic variation and adaptive significance in relation to pollen competition, delayed self-pollination and mating-system evolution. Amer. J. Bot. 94:1183-1192.

Lebuhn, G. and G.J. Anderson. 1994. Anther tripping and pollen dispensing in Berberis thunbergii. Amer. Midl. Nat. 131:257-265.

Lu, L., P.W. Fritsch, H. Wang, H.T. Li, D.Z. Li, and J.Q. Chen. 2009. Pollen morphology of Gaultheria L. and related genera of subfamily Vaccinioideae: Taxonomic and evolutionary significance. Rev. Palaeobot. Palynol. 154:106-123.

Mackenzie, C.J., B.Y. Yoo, and J.E.A. Seabrook. 1990. Stigma of Solanum tuberosum cv. 'Shepody': Morphology, ultrastructure, and secretion. Amer. J. Bot. 77:1111-1124.

Mert, C. and A. Soylu. 2007. Possible causes of low fruit set in the sweet cherry cultivar 0900 Ziraat. Can. J. Plant Sci. 87:593-594.

Nixon, K.C. and W.L. Crepet. 1993. Late Cretaceous fossil flowers of Ericalean affinity. Amer. J. Bot. 80:616-623.

Palser, B.F., J.L. Rouse, and E.G. Williams. 1992. A scanning electron microscope study of the pollen tube pathway in pistils of Rhododendron. Can. J. Bot. 70:1039-1060.

Patrick, T., J. Allsison, and G. Krakow. 1995. Protected plants of Georgia. Georgia Dept. Natural Resources, Social Circle, GA.

Porter, J. 2010. Conserving our botanical heritage: Using GPS/GIS and molecular analysis as conservation management tools for georgia plume (Elliottia racemosa). M.S. thesis, Univ. of Georgia, Athens, GA.

Santamour F.S., Jr. 1967. Cytology and sterility in Elliottia racemosa. Univ. Pennsylvania. Morris Arboretum Bul. 18:60-63.

Schmidt-Adam, G. and B.G. Murray. 2002. Structure and histochemistry of the stigma and style of Metrosideros excelsa. N.Z. J. Bot. 40:95-103.
Shivanna, K.R. 2003. Pollen development. Pollen biology and biotechnology. Science Publishers, Enfield, NH.

Slater, A.T. and D.M. Calder. 1990. Fine structure of the wet, detached cell stigma of the orchid Dendrobium speciosum Sm. Sex. Plant Reprod. 3:61-69.

Smithhuerta, N.L. 1991. Branching pollen tubes in the genus Clarkia, and evolutionary response to viscin threads. Evol. Trends Plants 5: $125-130$

Takayama, S. and A. Isogai. 2005. Self-incompatibility in plants. Annu. Rev. Plant Biol. 56:467-489.

Wetzstein, H.Y. and W. Yi. 2010. Tissue culture as a conservation strategy for the safeguarding and reintroduction of georgia plume. Tipularia (in press).

Wilcock, C. and R. Neiland. 2002. Pollination failure in plants: Why it happens and when it matters. Trends Plant Sci. 7:270-277.

Williams, E.G. and J.L. Rouse. 1990. Relationships of pollen size, pistil length and pollen tube growth rates in Rhododendron and their influence on hybridization. Sex. Plant Reprod. 3:7-17.

Woo, S.M. and H.Y. Wetzstein. 2008a. Morphological and histological evaluations of in vitro regeneration in Elliottia racemosa leaf explants induced on media with thidiazuron. J. Amer. Soc. Hort. Sci. 133:167-172.

Woo, S.M. and H.Y. Wetzstein. 2008b. An efficient tissue culture regeneration system for georgia plume, Elliottia racemosa, a threatened Georgia endemic. HortScience 43:447-453.

Yi, W.G., S.E. Law, D. McCoy, and H.Y. Wetzstein. 2006. Stigma development and receptivity in almond (Prunus dulcis). Ann. Bot. (Lond.) 97:57-63.

Yi, W.G., S.E. Law, and H.Y. Wetzstein. 2003. An in vitro study of fungicide effects on pollen germination and tube growth in almond. HortScience 38:1086-1088.

Zomlefer, W.B. 1994. Guide to flowering plant families. University of North Carolina Press, Chapel Hill, NC. 